\title{
COMPARISON OF RIPASA AND ALVARADO SCORE IN DIAGNOSIS OF ACUTE APPENDICITIS
}

\author{
Iswara Chandra Muduli1, Bismaya Kumar Rout2, Swarupa Nanda Mallick ${ }^{3}$
}

${ }^{1}$ Associate Professor, Department of General Surgery, MKCG Medical College, Berhampur, Odisha.

2 Post Graduate, Department of General Surgery, MKCG Medical College, Berhampur, Odisha.

${ }^{3}$ Assistant Professor, Department of General Surgery, MKCG Medical College, Berhampur, Odisha.

\section{ABSTRACT}

\section{BACKGROUND}

Acute appendicitis remains the most frequent cause for emergency operations in gastrointestinal surgery. Its diagnosis relies largely on clinical assessment. Multiple scoring systems have been developed in order to identify those patients who need emergency appendicectomy of which the Alvarado score was most popular. The accuracy of Alvarado score in the diagnosis of acute appendicitis is disappointingly low in Asian population and RIPASA scoring has been designed. Here, we prospectively compared the RIPASA and Alvarado score in Indian population.

\section{MATERIAL AND METHODS}

We compared the RIPASA and Alvarado scores for diagnosis of acute appendicitis by applying them to 105 patients who presented with right iliac fossa pain during the study period. Both the RIPASA and Alvarado scores were derived, but decisions for appendicectomy was based on clinical judgment. Postoperative histopathology report was correlated with the scores. Sensitivity, specificity, Positive Predictive Value (PPV) and Negative Predictive Value (NPV), diagnostic accuracy for RIPASA and Alvarado system was derived.

\section{RESULT}

At the optimal cut-off threshold score of 7.5 for the RIPASA score, the calculated sensitivity and specificity were $97.26 \%$ and $75 \%$ respectively compared with $68.49 \%$ and $84.37 \%$ respectively for Alvarado score at an optimal cut-off threshold of 7.0.

\section{CONCLUSION}

The RIPASA score is a better diagnostic scoring system for acute appendicitis compared to the Alvarado score with the former achieving significantly higher sensitivity, NPV and diagnostic accuracy, particularly in our population setting.

\section{KEYWORDS}

Acute Appendicitis, Appendicectomy, RIPASA, Alvarado.

HOW TO CITE THIS ARTICLE: Muduli IC, Rout BK, Mallick SN. Comparison of RIPASA and Alvarado score in diagnosis of acute appendicitis. J. Evolution Med. Dent. Sci. 2016;5(33):1794-1798, DOI: 10.14260/jemds/2016/423

\section{INTRODUCTION}

Acute appendicitis remains the most frequent cause for emergency operations in gastrointestinal surgery. Individual lifetime risk of appendicectomy due to acute appendicitis is $8.6 \%$ and $6.7 \%$ in male and female respectively. ${ }^{1,2}$ and at the age of 25 yrs. the male:female ratio reaches its peak i.e. 3:2.1 Its diagnosis relies largely on clinical assessment, although both ultrasound and Computed Tomography (CT) can be helpful. $^{3}$ A high percentage of negative appendectomies (20\%) was considered reasonable, based on the premise that delay would inevitably lead to perforation and thus increased morbidity even mortality. ${ }^{4}$ The cost to both the patient and the health care system of negative appendicectomy is considerable and a complication rate of up to $6.1 \%$ following removal of normal appendices was reported. 5 Multiple scoring systems have been developed in order to identify those patients who need emergency appendicectomy thus avoiding the risk of delay as well as identifying patients

Financial or Other, Competing Interest: None.

Submission 03-03-2016, Peer Review 31-03-2016,

Acceptance 06-04-2016, Published 22-04-2016.

Corresponding Author:

Dr. Bismaya Kumar Rout,

Final Year Post Graduate

Department of General Surgery,

MKCG Medical College,

Berhampur, Odisha.

E-mail:drbismayarout@gmail.com

DOI: $10.14260 /$ jemds $/ 2016 / 423$ unlikely to need surgery, thus decreasing the burden of negative appendicectomies. Of these, Alvarado score system described by Alfredo Alvarado in 1986 was most widely studied. The use of the Alvarado score system can reduce the negative appendicectomy rate to $0-5 \% .6,7$

This scoring system contains 8 (Eight) parameters like migration of pain from umbilical area to right iliac fossa, loss of appetite, nausea and vomiting, tenderness in right iliac fossa, sign of peritoneal inflammation like rebound tenderness, fever, increase in leucocyte count, appearance segmented neutrophils in peripheral smear (Shift to Left). Each parameter is assigned a score ranging from 1 to 2 and summation of score will guide the treatment modality. A score of 7 is taken as cut-off and patient having score beyond that are offered appendicectomy.

In 2010, a group in Raja Isteri Pengiran Anak Saleha (RIPAS) Hospital, in Brunei, developed a new scoring system called RIPASA score and claimed that it was more suitable for Asian and Middle East populations than Alvarado scoring system. ${ }^{8}$ The parameters they have included are - the patients' demographics, i.e. National Registration Identity Card [NRIC] number, age and gender; the presenting symptoms, i.e. RIF pain, the migration of pain to the RIF, nausea and vomiting, anorexia and the duration of symptoms; clinical signs, i.e. RIF tenderness, guarding, rebound tenderness, Rovsing's sign and fever; and laboratory investigations, i.e. elevated white cell count and negative urinalysis (Absence of Blood, Neutrophils or Bacteria). 
The RIPASA score sheet consists of 14 fixed parameters with an additional parameter for patients who held foreign National Record of Identity Card (NRIC), which is specific to local population where the score was developed. Each parameter is assigned a score ranging from 0.5 to 2 and the total score can guide the treatment. A score of 7.5 is taken as cut-off and patient having score above this are offered appendicectomy. The RIPASA score is a new diagnostic scoring system developed for the diagnosis of acute appendicitis and has been shown to have significantly higher sensitivity, specificity and diagnostic accuracy than that reported for the Alvarado, particularly when the latter score was applied in Asian or oriental population. ${ }^{9}$

Although the RIPASA score is more extensive than the Alvarado score, it is simple to apply and has several parameters that are absent in the Alvarado score such as age, gender and duration of symptoms prior to presentation. These parameters have been shown to affect the sensitivity and specificity of the Alvarado score. ${ }^{10}$ We prospectively compared RIPASA and Alvarado score in terms of sensitivity, specificity, positive and negative predictive value, diagnostic accuracy; by applying them to the patients attending our hospital with right iliac fossa pain that could probably be acute appendicitis, during the period September 2013 to August 2015.

\section{METHODS}

A prospective study was conducted during the period from September 2013 to August 2015 in various surgical units of $M$ K. C. G. Medical College Hospital, Berhampur. Ethical approval to conduct the study was granted by the Medical and Health Review Ethics Committee at M. K. C. G. Medical College and Hospital. Patients who were presented with Right Iliac Fossa (RIF) pain and diagnosed as acute appendicitis from clinical and other diagnostic investigations were included in the study. Patient coming to hospital with pain abdomen along with distension of abdomen, pregnant females, mass per abdomen, patient not willing for surgery were not included.

Upon admission, thorough history taking and clinical examination was done in all the patients and all necessary investigations were done. The cases subjected to emergency surgery were adequately prepared.

Depending on individual presentation of signs and symptoms, both RIPASA and ALVARADO scores were calculated for each case of suspected appendicitis by completing the score sheets. Scoring was carried out by the admitting surgeon. Neither of the evaluation score sheets used during the study contained the actual scores and guidelines, so that the total scores did not bias the judgement of the admitting surgeon with respect to appendicectomy, which was solely based on the surgeon's own clinical judgement.

The Table 01 and 02 shows the parameters included in RIPASA and Alvarado scores and corresponding points assigned to each parameter. The RIPASA score sheet consisted of 14 fixed parameters with an additional parameter for patients who held foreign National Record of Identity Card (NRIC). The Alvarado score sheet contained the standard eight parameters.

\begin{tabular}{|c|c|c|}
\hline 1. & Male & 1.0 \\
& Female & 0.5 \\
\hline 2. & Age $<39.9$ yrs. & 1.0 \\
& Age $>40$ yrs. & 0.5 \\
\hline 3. & RIF pain & 0.5 \\
\hline 4. & Migration of RLQ pain & 0.5 \\
\hline 5. & Anorexia & 1.0 \\
\hline 6. & Nausea and Vomiting & 1.0 \\
\hline 7. & Duration of symptoms $<48$ hrs. & 1.0 \\
& Duration of symptom $>48$ hrs. & 0.5 \\
\hline 8. & RIF tenderness & 1.0 \\
\hline 9. & RIF Guarding & 2.0 \\
\hline 10. & Rebound Tenderness & 1.0 \\
\hline 11. & Rovsing's sign & 2.0 \\
\hline 12. & Fever & 1.0 \\
\hline 13. & Raised WCC & 1.0 \\
\hline 14. & Negative urinalysis \\
\hline \multicolumn{2}{|c|}{ Table 1: RIPASA Score Parameters } \\
\hline \multicolumn{2}{|c|}{} \\
\hline
\end{tabular}

Total score is achieved by adding all the score for each category together. Guidelines for management according to total score:

- $\quad<5=$ Probability of acute appendicitis is unlikely; observe patient in A and E Day Ward and repeat scoring after 1-2 hrs. If reducing score, discharge. If increasing score, treat according to score level.

- 5-7.0 = Low probability of acute appendicitis; observe in A and E Day Ward and repeat scoring after 1-2 hrs. or perform abdominal ultrasound investigations to rule out acute appendicitis.

- 7.5-11.0 = Probability of acute appendicitis is high; refer patient to on-call surgeon for admission and repeat score in 1-2 hrs. time. If remains high, prepare patient for appendicectomy procedure.

- $\quad>12$ = Definite acute appendicitis; refer to surgeon on-call for admission and appendicectomy.

*The original score has additional parameter: foreign National Record of Identity Card (NRIC), which is specific to the local population where the system was developed.

\begin{tabular}{|c|c|c|}
\hline 1. & Migratory right iliac fossa pain & 1 point \\
\hline 2. & Anorexia & 1 point \\
\hline 3. & Nausea and Vomiting & 1 point \\
\hline 4. & Right iliac fossa tenderness & 2 point \\
\hline 5. & Rebound tenderness & 1 point \\
\hline 6. & Fever & 1 point \\
\hline 7. & Leucocytosis & 2 point \\
\hline 8. & Shift to left (Segmented neutrophils) & 1 point \\
\hline \multicolumn{3}{|c|}{ Table 2: Alvarado Score Parameters } \\
\hline
\end{tabular}

Guidelines

$\begin{array}{cl}1-4 & \text { Appendicitis Unlikely } \\ 5-6 & \text { Appendicitis Possible } \\ 7-8 & \text { Appendicitis Probable } \\ >9 & \text { Appendicitis Definite }\end{array}$

Scoring was performed at every review until a decision was made for either appendicectomy or continued conservative observation/treatment. In all cases where appendicectomy was performed, the excised specimens were sent for histopathological study and the results were 
recorded. All patients treated conservatively were contacted via telephone within a month to confirm their true negative status as well as to verify that they had not been re-admitted and undergone emergency appendicectomy at MKCG, MCH or any other hospital.

All the data obtained were recorded and interpreted using chi-square test for their significant association and validity.

\section{OBSERVATION AND RESULTS}

Out of all patients recruited, only 105 patients satisfied to be included in the study after carefully evaluating the inclusion and exclusion criteria. Among these 74 were male and 31 were female, hence male:female ratio came to be $2.38: 1$. The demographics of these 105 patients are shown in Table 03 . The mean age of the patients was $23.5 \pm 9.42$ years. Again on the basis of surgeons' clinical judgment, 96 patients (Out of 105) underwent emergency appendicectomy and 9 patients were treated conservatively.

Out of these 96 appendicectomies, only 73 cases were confirmed histologically for acute appendicitis and six cases had perforated appendicitis (Table 03); 23 cases were negative for acute appendicitis and histology specimens showed normal appendix indicating a negative appendicectomy rate of $23.95 \%$. All the nine cases treated conservatively and discharged were contacted over phone to establish their true negativity. It was found that all the nine cases treated conservatively were negative for acute appendicitis. Hence, total no. of negative cases came to be 32 $(23+9)$.

The mean duration of hospital stay was $5.15 \pm 1.7$ (Range 3-16) days. Fourteen out of 96 (14.6\%) patients who underwent emergency appendicectomy developed postoperative complications like superficial skin infection, intra-abdominal sepsis (Table 03). All 105 patients were discharged alive.

\begin{tabular}{|c|c|c|}
\hline Demographic & No. & \% \\
\hline Gender & 74 & 70.4 \\
Male & 31 & 29.6 \\
Female & $23.5 \pm 9.42$ & \\
\hline Mean age \pm SD (yrs.) & & \\
Total emergency & 96 & \\
appendicectomy & 73 & 76.04 \\
Confirmed histology for acute & 23 & 23.95 \\
appendicitis & & \\
Negative histology for acute & & $3-16$ \\
appendicitis & $5.15 \pm 1.7$ & days \\
\hline Mean hospital stay \pm SD range \\
(days) & 6 & \\
\hline Perforated Appendicitis & 14 & 14.58 \\
\hline Postoperative complication & 11 & 11.46 \\
Superficial wound infection & 3 & 3.12 \\
Intra-abdominal sepsis/bowel & 0 & 100 \\
\hline obstruction & 105 & \\
\hline Haematuria (Traumatic) & Patient discharged alive & \multicolumn{2}{|c|}{ Table 3: Patient's Demographics } \\
\hline \multicolumn{2}{|c|}{}
\end{tabular}

Table 04 and 05 shows the distribution of patients in different score groups in RIPASA scoring like those with $<5$, 5-7, 7.5-12 and $>12$ and Alvarado scoring like those with 1-4, 5-6, 7-8 and >9. Again each group was distributed among patients underwent surgery and according to histological finding of the excised specimen. Each category was further divided into number of male and female patients. Thus total number of patients with RIPASA $<7.5$ came to be 26 , in which 22 underwent surgery and histology show 2 positive and 20 negative. Total number of patients with RIPASA $>7.5$ came to be 79 , in which 74 underwent surgery and histology show 71 positive and 3 negative.

\begin{tabular}{|c|c|c|c|c|}
\hline Score & $\begin{array}{c}\text { No. of } \\
\text { Patients } \\
\text { (Male: } \\
\text { Female) }\end{array}$ & $\begin{array}{c}\text { No. Under- } \\
\text { gone } \\
\text { Surgery } \\
\text { (Male: } \\
\text { Female) }\end{array}$ & $\begin{array}{c}\text { Histology } \\
\text { Positive } \\
\text { (Male: } \\
\text { Female) }\end{array}$ & $\begin{array}{c}\text { Histology } \\
\text { Negative } \\
\text { (Male: } \\
\text { Female) }\end{array}$ \\
\hline$<5$ & $14(11: 3)$ & $10(8: 2)$ & 0 & $10(8: 2)$ \\
\hline $5.0-7$ & $12(8: 4)$ & $12(8: 4)$ & $2(2: 0)$ & $10(6: 4)$ \\
\hline $\begin{array}{c}\text { RIPASA } \\
<7.5\end{array}$ & $26(19: 7)$ & $22(16: 6)$ & $2(2: 0)$ & $20(14: 6)$ \\
\hline $7.5-12$ & $76(52: 24)$ & $71(49: 22)$ & 68 & $3(2: 1)$ \\
\hline$>12$ & $3(3: 0)$ & $3(3: 0)$ & $3(3: 0)$ & 0 \\
\hline $\begin{array}{c}\text { RIPASA } \\
>7.5\end{array}$ & $79(55: 24)$ & $74(52: 22)$ & 71 & $3(2: 1)$ \\
\hline Total & $\mathbf{1 0 5}$ & $\mathbf{9 6}$ & $\mathbf{7 3}$ & $\mathbf{7 3}$ \\
\hline \multicolumn{5}{|r|}{} \\
\hline
\end{tabular}

Total number of patients with Alvarado $<7$ came to be 50 , in which 44 underwent surgery and histology show 23 positive and 21 negative. Total number of patients with Alvarado $>7$ came to be 55 , in which 52 underwent surgery and histology show 50 positive and 2 negative.

\begin{tabular}{|c|c|c|c|c|}
\hline Score & $\begin{array}{c}\text { No. of } \\
\text { Patient } \\
\text { (Male: } \\
\text { Female) }\end{array}$ & $\begin{array}{c}\text { No } \\
\text { Under- } \\
\text { gone } \\
\text { Surgery } \\
\text { (Male: } \\
\text { Female) }\end{array}$ & $\begin{array}{c}\text { Histology } \\
\text { Positive } \\
\text { (Male: } \\
\text { Female) }\end{array}$ & $\begin{array}{c}\text { Histo- } \\
\text { logy } \\
\text { Negative } \\
\text { (Male: } \\
\text { Female) }\end{array}$ \\
\hline $1-4$ & $26(18: 8)$ & $20(14: 6)$ & $10(7: 3)$ & $10(7: 3)$ \\
\hline $5-6$ & $24(19: 5)$ & $24(19: 5)$ & $13(11: 2)$ & $11(8: 3)$ \\
\hline $\begin{array}{c}\text { Alvarad } \\
\text { o } \\
<7\end{array}$ & $\begin{array}{c}50 \\
(37: 13)\end{array}$ & $\begin{array}{c}44 \\
(33: 11)\end{array}$ & $23(18: 5)$ & $\begin{array}{c}21 \\
(15: 6)\end{array}$ \\
\hline $7-8$ & $\begin{array}{c}53 \\
(35: 18)\end{array}$ & $\begin{array}{c}50 \\
(33: 17)\end{array}$ & $\begin{array}{c}48 \\
(32: 16)\end{array}$ & $2(1: 1)$ \\
\hline$>9$ & $2(2: 0)$ & $2(2: 0)$ & $2(2: 0)$ & 0 \\
\hline $\begin{array}{c}\text { Alvarad } \\
\text { o }\end{array}$ & $\begin{array}{c}55 \\
>7\end{array}$ & $\begin{array}{c}52 \\
(35: 18)\end{array}$ & $\begin{array}{c}50 \\
(34: 17)\end{array}$ & $2(1: 1)$ \\
\hline Total & $\mathbf{1 0 5}$ & $\mathbf{9 6}$ & $\mathbf{7 3}$ & $\mathbf{2 3}$ \\
\hline \multicolumn{5}{|c|}{ Table 5: Distribution of Alvarado Scores } \\
\hline
\end{tabular}

Table 06 compares the distribution of the 105 patients in four groups, i.e. true positive, false positive, true negative and false negative according to both the RIPASA score at a cut-off threshold score of 7.5 and the Alvarado score at a cutoff threshold of 7.0. 


\begin{tabular}{|c|c|c|c|c|c|c|c|c|}
\hline & \multicolumn{2}{|c|}{ True Positive } & \multicolumn{2}{|c|}{ False Positive } & \multicolumn{2}{|c|}{ True Negative } & \multicolumn{2}{|c|}{ False Negative } \\
\hline & $\begin{array}{c}\text { RIPASA } \\
>7.5\end{array}$ & $\begin{array}{l}\text { Alvarado } \\
>7\end{array}$ & $\begin{array}{l}\text { RIPASA } \\
>7.5\end{array}$ & $\begin{array}{c}\text { Alvarado } \\
>7\end{array}$ & $\begin{array}{c}\text { RIPASA } \\
<7.5\end{array}$ & $\begin{array}{l}\text { Alvarado } \\
<7\end{array}$ & $\begin{array}{c}\text { RIPASA } \\
<7.5\end{array}$ & $\begin{array}{c}\text { Alvarado } \\
<7\end{array}$ \\
\hline Sample Size & 71 & 50 & 8 & 5 & 24 & 27 & 2 & 23 \\
\hline Male:Female & $50: 21$ & $34: 16$ & $5: 3$ & $3: 2$ & $17: 7$ & 19:8 & $2: 0$ & $18: 5$ \\
\hline Mean age \pm SD (yrs.) & $26.32 \pm 9.7$ & $27.5 \pm 10.54$ & $18.75 \pm 7.51$ & $19.8 \pm 9.83$ & $18.25 \pm 5.49$ & $18.11 \pm 5.36$ & $19.5 \pm 2.12$ & $23.17 \pm 6.49$ \\
\hline $\begin{array}{c}\text { Mean Score } \pm \text { SD } \\
\text { Range }\end{array}$ & $\begin{array}{c}9.22 \pm 1.34 \\
7.5-13.5\end{array}$ & $\begin{array}{c}7.62 \pm 0.62 \\
7.0-10\end{array}$ & $\begin{array}{c}8.25 \pm 0.88 \\
7.5-10\end{array}$ & $\begin{array}{c}7.0 \pm 0 \\
7.0\end{array}$ & $\begin{array}{c}5.04 \pm 1.51 \\
3 .-7\end{array}$ & $\begin{array}{c}3.44 \pm 1.5 \\
1-6\end{array}$ & $\begin{array}{c}6.5 \pm 0.7 \\
6-7\end{array}$ & $\begin{array}{c}5.08 \pm 0.99 \\
3-6\end{array}$ \\
\hline $\begin{array}{c}\text { Mean Hospital } \\
\text { Stay } \pm \text { SD } \\
\text { Range (Days) }\end{array}$ & $\begin{array}{c}5.77 \pm 1.68 \\
3-16\end{array}$ & $\begin{array}{c}6.14 \pm 1.77 \\
4-16\end{array}$ & $\begin{array}{c}4.25 \pm 1.03 \\
3-6\end{array}$ & $\begin{array}{c}4.2 \pm 1.09 \\
3-6\end{array}$ & $\begin{array}{c}3.58 \pm 0.77 \\
2-5\end{array}$ & $\begin{array}{c}3.6 \pm 0.8 \\
2-6\end{array}$ & $\begin{array}{c}5.5 \pm 0.7 \\
5-6\end{array}$ & $\begin{array}{c}4.95 \pm 1.02 \\
3-7\end{array}$ \\
\hline
\end{tabular}

As seen in Table 06, the RIPASA score had correctly classified 71 (97.26\%) patients confirmed with histological acute appendicitis (73) to the high-probability group (RIPASA score $>7.5$ ), whereas the Alvarado score had classified only $50(68.49 \%)$ patients (Alvarado score $>7.0)$. The 23 patients who were missed by the Alvarado score were classified wrongly into the false negative group with Alvarado score $<7.0$. This number was significantly higher than those wrongly classified into false negative group by the RIPASA score, i.e. 2 (RIPASA <7.5). Both the RIPASA and Alvarado scores correctly classified 24 (75\%) and 27 (84.37\%) patients without acute appendicitis into the true negative group with scores $<7.5$ and $<7.0$, respectively.

The mean total RIPASA scores for each group are shown in Table 06. True positive cases achieved mean total RIPASA scores of $9.22 \pm 1.34$ (range 7.5-13.5), while true negative cases had mean scores of $5.04 \pm 1.51$ (range 3-7). Hospital stay was significantly longer in both the true positive and false negative groups compared to the true negative group, which corresponded with the longer postoperative period observed in the former, following emergency appendicectomy.

\begin{tabular}{|c|c|c|c|}
\hline \multirow{2}{*}{ Variable } & \multicolumn{2}{|c|}{ Scores in \% } & \multirow{2}{*}{ P value } \\
\cline { 2 - 3 } & $\begin{array}{c}\text { RIPASA } \\
\mathbf{7 7 . 5}\end{array}$ & $\begin{array}{c}\text { Alvarado } \\
\mathbf{7 7}\end{array}$ & \\
\hline Sensitivity & 97.26 & 68.49 & \multirow{2}{*}{0.0358} \\
\hline Specificity & 75 & 84.37 & \multirow{2}{*}{0.0173} \\
\hline $\begin{array}{c}\text { Positive predictive } \\
\text { value }\end{array}$ & 89.87 & 90.1 & \\
\hline $\begin{array}{c}\text { Negative predictive } \\
\text { value }\end{array}$ & 92.3 & 54 & \\
\hline Diagnostic accuracy & 90.47 & 73.33 & \\
\hline
\end{tabular}

\section{Table 7: Comparison between the RIPASA and Alvarado} Scoring Systems with Respect to Different Variables

At the optimal cut-off threshold score of 7.5 for the RIPASA score, the calculated sensitivity and specificity were $97.26 \%$ and $75 \%$ respectively compared with $68.49 \%$ and 84.37\% respectively for Alvarado score at an optimal cut-off threshold of 7.0 (Table 07). The p-value for these two variables in both the scores is 0.0358 , which shows there is significant association between these values. The Positive Predictive Value (PPV) and Negative Predictive Value (NPV) for the RIPASA score were $89.87 \%$ and $92.3 \%$ respectively compared with $90.1 \%$ and $54 \%$ respectively for the Alvarado score (Table 09). Again, the p-value is 0.0173 showing significant association. The negative predictive value of RIPASA score is significantly higher than that of Alvarado score. The diagnostic accuracy was $90.47 \%$ for the RIPASA score and $73.33 \%$ for the Alvarado score.

\section{DISCUSSION}

Acute appendicitis is one of the most common surgical emergencies and emergency appendicectomy is the commonest emergency surgery that account for one in ten of all emergency abdominal surgeries. Diagnosis of acute appendicitis largely relies on clinical assessment in many parts of the world. A quick and correct diagnosis of acute appendicitis leading to early appendicectomy and avoidance of complications arising from perforation can be difficult at times. Imaging modalities such as ultrasonography and Computed Tomography (CT) further aid in making a definite diagnosis. CT scan have been reported to have high sensitivity (94\%) and specificity (95\%) for diagnosing acute appendicitis. ${ }^{4}$ Further, assessment of $\mathrm{C}$-reactive protein aids in diagnosis. ${ }^{3}$ However, the cost of such investigation is high.

The Alvarado score, which was developed in 1986 was a simple additive scoring system to help with the diagnosis of acute appendicitis. ${ }^{6}$ although it showed very good sensitivity and specificity when applied in a Western population, several subsequent studies have shown its limitations when applied in an Asian or Oriental population. As a result, a new scoring system called the RIPASA score was developed, which was more extensive yet simple additive scoring system consisting of 14 fixed parameters and an additional parameter (NRIC) that is unique to Asian population setting. All these 15 parameters are easily obtainable from a good clinical history, examination and investigations.

This study compared the RIPASA and Alvarado scores in our patient population who presented with RIF pain and who were suspected of acute appendicitis. The RIPASA scored considerably better than the Alvarado score in terms of correctly diagnosing patients with acute appendicitis (Sensitivity and diagnostic accuracy) as well was found to be as those who were negative for acute appendicitis (NPV).

Using the RIPASA score, $97.26 \%$ of patients who actually had acute appendicitis were correctly diagnosed and placed in the high-probability group (RIPASA score $>7.5$ ) and managed appropriately, compared to only $68.49 \%$ when using the Alvarado score on the same population sample. Thus, the Alvarado score failed to diagnose $21.9 \%$ of patients $(n=23)$ with acute appendicitis and wrongly classified them in the low-probability group (Alvarado score <7.0). The difference in diagnostic accuracy of $17.14 \%$ between the RIPASA score and Alvarado score was significant indicating that the RIPASA score is a much better diagnostic tool for the diagnosis of acute appendicitis in our patient population, 
which is representative of a Southeast Asian population group.

Similarly, for patients who were classified in the lowprobability group, i.e. true negative group with RIPASA score $<7.5$ and Alvarado score $<7.0$, the RIPASA score again outperformed the Alvarado score by correctly diagnosing 92.3\% of patients who did not have acute appendicitis compared with the Alvarado score, which only managed to correctly diagnose $54 \%$. In a study by Chong et al. ${ }^{9}$ in the year 2011 (Year of Publication), they found that at the optimal cutoff threshold score of 7.5 for the RIPASA score, the calculated sensitivity and specificity were $98.02 \%$ and $81.32 \%$ respectively compared with $68.32 \%$ and $87.91 \%$ respectively for Alvarado score at an optimal cut-off threshold of 7.0 (Table 8). The PPV and NPV for the RIPASA score were $85.34 \%$ and $97.37 \%$ respectively compared with $86.25 \%$ and $71.43 \%$ respectively for the Alvarado score. The NPV was significantly higher for the RIPASA score compared to that for the Alvarado score $(\mathrm{p}<0.0001)$.

\begin{tabular}{|c|c|c|}
\hline Variable & RIPASA $>7.5$ & Alvarado $>7$ \\
\hline Sensitivity & 98.02 & 68.32 \\
\hline Specificity & 81.32 & 87.91 \\
\hline $\begin{array}{c}\text { Positive } \\
\text { predictive value }\end{array}$ & 85.34 & 86.25 \\
\hline $\begin{array}{c}\text { Negative } \\
\text { predictive value }\end{array}$ & 97.37 & 71.43 \\
\hline $\begin{array}{c}\text { Diagnostic } \\
\text { accuracy }\end{array}$ & 91.83 & 86.51 \\
\hline $\begin{array}{c}\text { Table 8: Comparison between the RIPASA and Alvarado } \\
\text { Scoring Systems with Respect to Different Variables as } \\
\text { by Chong et al. }\end{array}$ \\
\hline
\end{tabular}

The RIPASA score is a useful, rapid diagnostic tool for acute appendicitis, especially in the emergency settings as it requires only the patient's demographics (Age, Gender and Nationality, which are all available on registration), a good clinical history (RIF pain, migration to RIF, anorexia, nausea and vomiting), clinical examination (RIF tenderness, localised guarding, rebound tenderness, Rovsing's sign and fever) and two simple investigations (Raised white cell count and negative urine analysis performed at triage, which is defined as an absence of red and white blood cells, bacteria and nitrates).

Thus, in emergency setting, the casualty medical officer can make a quick decision upon seeing patients with RIF pain, by referring those with a RIPASA score $>7.5$ to the on-call surgical team for admission, while patients with a RIPASA score $<7.0$ can either be observed in the unit's day ward or discharged with an early clinic review appointment. The use of a numerical score also improves the working relationships between the casualty officer and the on-call surgeon, since any patient with a RIPASA score $\geq 7.5$ needs to be admitted.

Based on the findings of this study, our hospital admission of patients with RIF pain during this two-year period could be reduced, resulting in substantial healthcare cost savings. With its high sensitivity (97.26\%) and NPV (92.3\%), the RIPASA score can also help to reduce unnecessary and expensive radiological investigations such as routine CT imaging, thus further helping to reduce annual healthcare expenditure.

Thus to conclude, the RIPASA score is a better diagnostic scoring system for acute appendicitis compared to the Alvarado score. It achieves significantly higher sensitivity, NPV and diagnostic accuracy, particularly in our population setting. It will reduce unnecessary hospital admission, healthcare cost and radiological investigation.

\section{REFERENCES}

1. Ronan O'Connell P. The vermiform appendix; In: Bailey Love's short practice of surgery. Norman S Williams, Christopher JK Bulstrode, Ronan O'Connell P, ed. London: CRC Press, Taylor \& Francis Group, 2013;26 th ed:1199214.

2. Mike K Liang, Roland E Andersson, Bernard M Jaffe, et al. The appendix; In: Schwartz's principles of surgery; Schwartz SI, ed. McGraw Hill, 2014;10th edn:1241-59.

3. Sengupta A, Bax G, Paterson-Brown S. White cell count and C-reactive protein measurement in patients with possible appendicitis. Ann $\mathrm{R}$ Coll Surg Engl 2009;91(2):113-5.

4. Toorenvliet BR, Wiersma F, Babker RF, et al. Routine ultrasound and mimited computed tomography for the diagnosis of acute appendicitis. World J Surg 2010;34(10):2278-85.

5. Khairy G. Acute appendicitis: is removal of a normal appendix still existing and can we reduce its rate? Saudi J Gastroenterol 2009;15(3):167-70.

6. Alvarado A. A practical score for the early diagnosis of acute appendicitis. Ann Emerg Med 1986;15(5):557-64.

7. Kalan M, Rich AJ, Talbot D, et al. Evaluation of the modified alvarado score in the diagnosis of acute appendicitis: a prospective study. Ann R Coll Surg Engl 1994;76(6):418-9.

8. Chong CF, Adi MI, Thien A, et al. Development of the RIPASA score: a new appendicitis scoring system for the diagnosis of acute appendicitis. Singapore Med J 2010;51(3):220-5.

9. Chong CF, Thien A, Mackie AJA, et al. Evaluation of the RIPASA score: a new appendicitis scoring system for the diagnosis of acute appendicitis. Brunei Int Med J 2010;6(1):17-26.

10. Wani MM, Yousaf MN, Khan MA, et al. Usefulness of the alvarado scoring system with respect to age, sex and time of presentation, with regression analysis of individual parameters. Internet J Surg 2007;11(2). Available at: www.ispub/com/journal/the_internet_journal_of_surgery /archive/ volume_11_number_2.html. Accessed July 1, 2008. 